
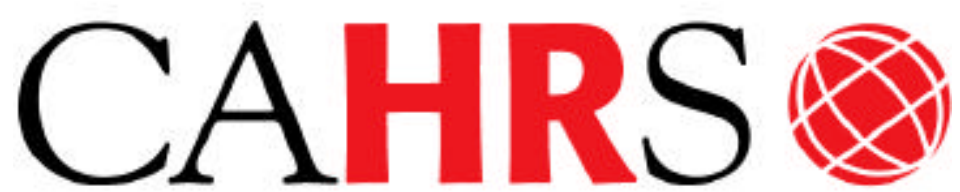

Center for Advanced Human Resource Studies
CAHRS / Cornell University 187 Ives Hall

Ithaca, NY 14853-3901 USA

Tel. 607 255-9358

www.ilr.cornell.edu/CAHRS/

Working Paper Serles

\title{
Employee Participation in Pollution Reduction: Preliminary Analysis of the Toxics Release Inventory
}

John Bunge

Edward Cohen-Rosenthal

S. Anontio Ruiz-Quintanilla

Working Paper 95-15 


\title{
Employee Participation in Pollution Reduction: Preliminary Analysis of the Toxics Release Inventory
}

\author{
John Bunge \\ Edward Cohen-Rosenthal \\ S. Antonio Ruiz-Quintanilla \\ Center for Advanced Human Resource Studies \\ ILR/Cornell University \\ Ithaca, NY 14853-3901
}

Working Paper 95-15

www.ilr.cornell.edu/cahrs

This paper has not undergone formal review or approval of the faculty of the ILR School. It is intended to make results of research, conferences, and projects available to others interested in human resource management in preliminary form to encourage discussion and suggestions. 


\begin{abstract}
Can the amount of toxic waste released into the environment by manufacturing facilities be reduced by formally involving employees in pollution prevention? Pursuant to the Pollution Prevention Act of 1990, the U.S. Environmental Protection Agency began requiring that manufacturers report human resource management strategies related to "source reduction" (reduction of waste at the source), as part of the Toxics Release Inventory (TRI). These strategies often involve employee participation in some form. Here we report the preliminary findings of an ongoing study of the effect of employee participation on source reduction, based on the 1991-1992 TRI database. We find, for example, that manufacturers using a certain combination of three formal employee participation practices had triple the reduction in emissions of manufacturers using none of these practices. We also discuss competing predictors of source reduction, and future research directions.
\end{abstract}




\section{Contents}

1 Introduction $\quad 2$

2 Overview and structure of the data 3

3 Basic approach and results $\quad 4$

3.1 Formal employee involvement methods $\ldots \ldots \ldots \ldots \ldots \ldots \ldots \ldots \ldots \ldots \ldots \ldots \ldots \ldots$

3.2 Employee involvement and external factors $\ldots \ldots \ldots \ldots \ldots \ldots \ldots \ldots \ldots$

4 Discussion $\quad 9$

5 Research directions $\quad 11$ 


\section{Introduction}

Increasing public awareness of environmental problems has resulted in increasing demands for corporate environmental accountability. Such demands are formalized eternally via federal, state, and local government regulations. But there is also growing internal corporate recognition that proactive environmental management is good business, both directly in terms of cost reduction (e.g.. avoidance of disposal and cleanup costs or fines), and indirectly in terms of public perception and good will. (For current literature on this subject, see Work and the Environment Bibliography. WEI 1994; a previous, related study was done by Kornbluh, Crowfoot. and Cohen-Rosenthal (1985)). Is there a role for human resource managers in pollution prevention? Our preliminary data analysis, discussed herein, indicates that the answer is "yes." Specifically, our results support the hypothesis that the amount of toxic waste released into the environment by manufacturing facilities can be reduced by formally involving employees in pollution prevention activities.

One such activity is "source reduction," defined by the federal Pollution Prevention Act of 1990 (PL 101-508) as any practice that

"reduces the amount of any hazardous substance, pollutant, or contaminant entering any waste stream or otherwise released into the environment (including fugitive emissions); and reduces the hazards to public health and the environment associated with the release of such substances, pollutants, or contaminants."

It has recently become possible to assess, quantitatively, the effect of employee participation programs on source reduction, using the Environmental Protection Agency's Toxics Release Inventory data. We are making the first detailed analysis of this data from this perspective.

Any manufacturing facility with 10 or more full-time employees that meets certain thresholds for processing toxic chemicals (over 300 such chemicals are so defined) must file a report, called EPA Form $\mathrm{R}$, for each chemical processed at the facility during a given calendar year. The data is then made available to the public by the EPA under the name Toxics Release Inventory (TRI). In the reporting year 1991 (the fifth year of the program) certain changes were made to Form R, pursuant to the Pollution Prevention Act of 1990.

"Beginning with the 1991 reports, facilities are required to provide additional information about waste management and source reduction activities. New data elements include ... source reduction activities, and methods used to identify those activities. Availability of these data will provide a more complete picture of total waste generation and management by facilities, and will increase the ability to track progress in moving towards less waste generation and safer management alternatives" (EPA 1993; emphasis added). 
Several of the "methods used to identify" source reduction activities, or "source reduction methods," can be mapped to HR management practices. Thus the availability of source reduction method information in the $\mathrm{TRI}$ database gives us an unprecedented opportunity to assess outcomes of proactive environmental HR management strategies. Our preliminary analysis shows that formal involvement of employees in source reduction is associated with dramatically greater year-to-year reductions in toxic releases to the environment.

This report is organized as follows. In $\S 2$ we give a broad overview of the relevant TRI data, in $\S 3$ we describe our basic approach and results, in $\S 4$ we discuss the implications of our findings, and in $\S 5$ we discuss further research directions.

\section{Overview and structure of the data}

Our analysis relates source reduction methods to the quantity of source reduction. i.e., the change in toxic releases from year to year (adjusted for production: see below). We used 1991-1992 as our two-year period for analysis. (Source reduction methods were reported for the first time in 1991. so in principle it would be possible to replicate our analyses for 1990-1991. but according to the EPA the data for the first reporting year is less reliable.)

Each TRI Form R represents a single chemical substance at a single facility. In 1992, 81.016 forms were submitted, representing 23,630 facilities. Of these, 20,508 forms (8,492 facilities) indicated implementation of source reduction. We were able to match 13,083 of these forms with the corresponding 1991 form for the same chemical at the same facility. After deleting forms with 1992 "production ratio" (see below) less than 0 or greater than 10, 12,482 forms remained. Of these, 12.323 indicated some source reduction method.

To compute a measure of year-to-year change in toxic releases, adjusted for changes in production, we essentially followed the procedure recommended by the EPA (EPA, 1993, p.132), with some alterations. We defined relative change in toxic releases from 1991 to 1992 , adjusted for changes in production, called "PREL," as ${ }^{1}$

${ }^{1}$ This computation differs slightly from that used by the EPA: we only used "quantity released," Form R Section 8.1, while the EPA used the sum of Sections 8.1-8.7; we used the actual 1991 quantity released as reported on the 1991 form, while the EPA used the 1991 quantity as reported for the "previous year" on the 1992 form; and we deleted forms with production ratio less than 0 or greater than 10, while the EPA used all forms. 


$$
\begin{aligned}
\text { PREL }= & \frac{1992 \text { releases }-1991 \text { releases adjusted for production }}{1991 \text { releases }} \times 100 \% \\
= & \frac{1992 \text { releases }-1991 \text { releases } \times \frac{1992 \text { production }}{1991 \text { production }}}{1991 \text { releases }} \times 100 \%
\end{aligned}
$$

The 1992 "production ratio," (1992 production) /(1991 production), is supplied on form R by the respondent. We were finally able to compute PREL for 10,910 forms. All results reported herein are based on these forms.

The source reduction activities and methods information is reported in Section 8 of Form

\begin{tabular}{|c|c|c|}
\hline Code & Source reduction method & Group \\
\hline${ }^{\star} \mathrm{T}$ T01 & Internal pollution prevention opportunity audit(s) & \\
\hline T02 & External pollution prevention opportunity audit(s) & Audits \\
\hline T03 & Materials balance audits & \\
\hline *T04 & Participative team management & Employee- \\
\hline T05 & Employee recommendation (independent of a formal company program) & based \\
\hline *T06 & Employee recommendation (under a formal company program) & strategies \\
\hline T07 & State government technical assistance program & \\
\hline T08 & Federal government technical assistance program & External \\
\hline T09 & Trade association/industry technical assistance program & assistance \\
\hline T10 & Vendor assistance & \\
\hline T11 & Other & Other \\
\hline
\end{tabular}
R (see Appendix 1). The respondent may report up to four source reduction activities, each of which is selected from a list of 77 possible categories. For each reported source reduction activity, the respondent may report up to three "methods to identify activity" or source reduction methods. each of which is selected from the following list of 11 categories:

\section{Table 1: TRI Form $R$ source reduction methods}

The TRI documents do not give detailed descriptions of the source reduction methods. We provisionally grouped the methods as shown in the right-hand column of Table 1. We then provisionally identified methods T01 (Internal pollution prevention opportunity audit(s)), T04 (Participative team management), and T06 (Employee recommendation (under a formal company program)) as representing formal or company sponsored employee involvement programs (marked * in Table 1). ${ }^{2}$ In this preliminary analysis we categorize forms by various

${ }^{2}$ We regard this as a reasonably conservative assumption. We are fairly confident that these codes represent formal employee involvement programs, although this list may not be ideal; see $\$ 3.1$ and $\S 4$. 
combinations of source reduction methods (especially T01, T04, and T06), and we then study differences in PREL relative to these categories.

\section{Basic approach and results}

Our basic question is: "Does formal involvement of employees in source reduction lead to greater reduction in toxic releases?" Since statistical analysis can at most reveal association rather than a causal relation, we restate this as "Is formal employee involvement in source reduction associated with greater reduction in toxic releases?" The following "broad-brush" results do support this hypothesis.

We take PREL (relative change in toxic releases from 1991 to 1992, adjusted for production) to be our dependent variable, and source reduction method to be our independent variable. Essentially, we subdivide the dataset into categories based on various combinations of source reduction methods, and we compare median PREL across categories. We use median rather than mean PREL because the data is highly variable and somewhat error-prone, and the median is more resistant to perturbation by extreme values. Thus these results can be considered conservative. While there are formal statistical tests for equality of medians in different groups. we do not report the results of these tests here. As we will see below, the difference in medians is often quite large, and hypothesis tests for equality vs. difference of medians give "highly significant" results. but in the absence of a formal statistical model such tests are not interpretable. (We discuss some possible models in §5.)

Overall median PREL was $-6.9 \%$, that is, there was a median $6.9 \%$ decrease in toxic releases in our dataset of 10.910 forms. The overall interquartile range or "iqr" was $50 \%$. For a general overview, we first split the dataset according to presence or absence of a single source reduction method; Table 2 shows median PREL relative to these splits.

${ }^{3}$ The iqr is the distance between the first and third quartiles of PREL; it is a measure of spread or dispersion. Thus in the full dataset of 10,910 forms, the first quartile (25th percentile) of PREL was $-36.8 \%$ and the third quartile (75th percentile) was $+13.0 \%$, for an iqr of $+13-(-36.8)=49.8 \approx 50$. 


\begin{tabular}{|l|c|c|c|}
\hline Source reduction method & \# forms & Median PREL & iqr \\
\hline T01 - Internal audit & 4168 & -9.1 & 51 \\
not T01 & 6742 & -5.7 & 50 \\
\hline T02 - External audit & 382 & -8.0 & 62 \\
not T02 & 10528 & -6.8 & 49 \\
\hline T03 - Materials audit & 1163 & -8.1 & 47 \\
not T03 & 9747 & -6.7 & 50 \\
\hline T04 - Part. team mgmt. & 4873 & -7.3 & 50 \\
not T04 & 6037 & -6.5 & 49 \\
\hline T05 - Informal empl. rec. & 1729 & -4.0 & 52 \\
not T05 & 9181 & -7.5 & 50 \\
\hline T06 - Formal empl. rec. & 1058 & -10.0 & 50 \\
not T06 & 9852 & -6.5 & 50 \\
\hline T07 - State tech. asst. & 71 & -3.0 & 67 \\
not T07 & 10839 & -6.9 & 50 \\
\hline T08 - Federal tech. asst. & 22 & -13.8 & 44 \\
not T08 & 10888 & -6.9 & 50 \\
\hline T09 - Trade assoc. asst. & 511 & -1.1 & 52 \\
not T09 & 10399 & -7.1 & 50 \\
\hline T10 - Vendor asst. & 1995 & -6.4 & 42 \\
not T10 & 8915 & -7.0 & 51 \\
\hline T11 - Other & 1662 & -5.7 & 51 \\
not T11 & 9248 & -7.0 & 49 \\
\hline
\end{tabular}

Table 2: Comparison of PREL by single source reduction method.

For example, code T01 (Internal pollution prevention opportunity audit(s)) was reported on 4168 forms; 6742 forms did not report T01 $(4168+6742=10910)$. Median PREL in the two groups was $-9.1 \%$ and $-5.7 \%$ respectively; that is, there was a median $9.1 \%$ percent reduction in toxic releases in the first group vs. a median $5.7 \%$ reduction in the second group. We report the iqr solely to give an idea of the dispersion of PREL in the various groups; it is not a "standard error."

\subsection{Formal employee involvement methods}

For a more detailed view we consider combinations of methods. Source reduction activities and methods are decoupled in the TRI database, so that for each form there is simply a list of all reported activities and a list of all reported methods. In principle, any number of source reduction methods, from none up to all 11, may be reported. For reasons of space and simplicity we retained only the first three methods reported. In our dataset there were 159 forms reporting no methods, 6626 reporting exactly one, 3564 reporting exactly two, and 2133 reporting three or more. (Fewer than 1000 forms reported more than three.) Thus in our dataset a form may show up to three of 11 possible responses. This yields a total of 232 possible combinations of source 
reduction methods. ${ }^{4}$ In fact, only 147 combinations occurred in the data, and most of these occurred very few times. However, this is still too many categories to deal with directly. Instead, and in keeping with our primary goals, we focus first on combinations of T01 (Internal pollution prevention opportunity audit(s)), T04 (Participative team management), and T06 (Employee recommendation (under a formal company program)) as representing formal or company sponsored employee involvement programs. Table 3 contrasts forms reporting two- and three-way combinations of these methods with forms reporting neither or none of these methods.

\begin{tabular}{|l|l|l|l|}
\hline Source reduction method & \# forms & Median PREL & iqr \\
\hline T01 \& T04 & 1642 & -10.0 & 51 \\
not T01\& not T04 & 3511 & -5.3 & 49 \\
\hline TOI \& T06 & 362 & -15.7 & 64 \\
not T01 \& not T06 & 6046 & -5.5 & 50 \\
\hline T04 \& T06 & 507 & -10.0 & 50 \\
not T04 \& not T06 & 5486 & -6.0 & 49 \\
\hline T01 \& T04 \& T06 & 213 & -15.8 & 63 \\
not T01 \& not T04 \& not T06 & 3109 & -5.0 & 50 \\
\hline
\end{tabular}

Table 3: Comparison of PREL by combinations of T01, T04, and T06.

Note the dramatic increase in source reduction in the last category, namely those forms reporting all three "employee involvement methods" T01, T04, and T06. These 213 forms represent 76 facilities belonging to 60 parent companies, spread across 31 states. Among these forms, 51 different Standard Industrial Codes are represented, from the categories of food products, furniture, paper, chemicals, petroleum, rubber, leather, concrete, steel, metal, industrial machinery and computers, electronic equipment, and transportation equipment. Sixty-nine different chemicals are represented. Thus the improvement in source reduction in this group, while possibly influenced by factors other than source reduction methods, is not obviously attributable to company, region, industrial type or chemical processed.

We next look at internal relationships between the methods T01. T04. and T06. Figure 1 displays all possible combinations of these methods; each part of the diagram is labeled with the number of forms. median PREL, and iqr for the corresponding combination.

\footnotetext{
${ }^{4}$ No methods reported (1 possibility), exactly one (11 possibilities), exactly two (55 possibilities),
} or exactly three (165 possibilities). 


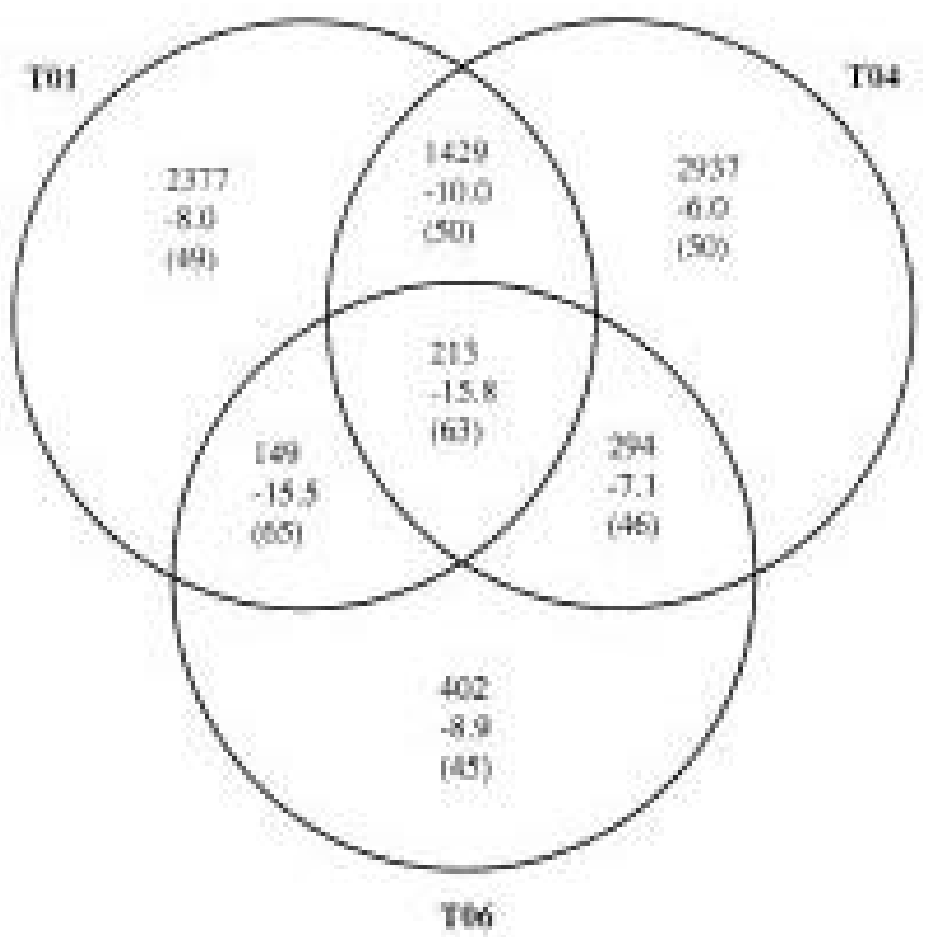

Figure 1: Felationglep of 701, T04, and TH.

The interpretation of Figure 1 is not entirely straightforward. The effect on source reduction is strongest when all three are reported., but the T01 \& T06 combination is also competitive without T04. Given that source reduction methods are defined only by the short phrases cited in Table 1, the distinctions between T01, T04, and T06 are probably not clearly drawn for TRI respondents. It may be, for example, that T04 (Participative team management) and T06 (Employee recommendation (under a formal company program)) are closely related, but distinct from TO1 (Internal pollution prevention opportunity audit(s)). Further research is needed to clarify the relationships among these methods.

\subsection{Employee involvement and external factors}

In fact four three-way combinations of source reduction methods occurred in the data in substantial numbers: T01, T04, and T06; T01, T04, and T05 (= Employee recommendation (independent of a formal company program)); T01, T04, and T03 (= Materials balance audits): and T01, T04, and T10 (= Vendor assistance). The first of these was considered above, and we do not further study the second, since T05 always shows detrimental results (cf. Table 1). For T01 (Internal pollution prevention opportunity audit(s)). T04 (Participative team management), and T03 (Materials balance audits), see Figure 2. 


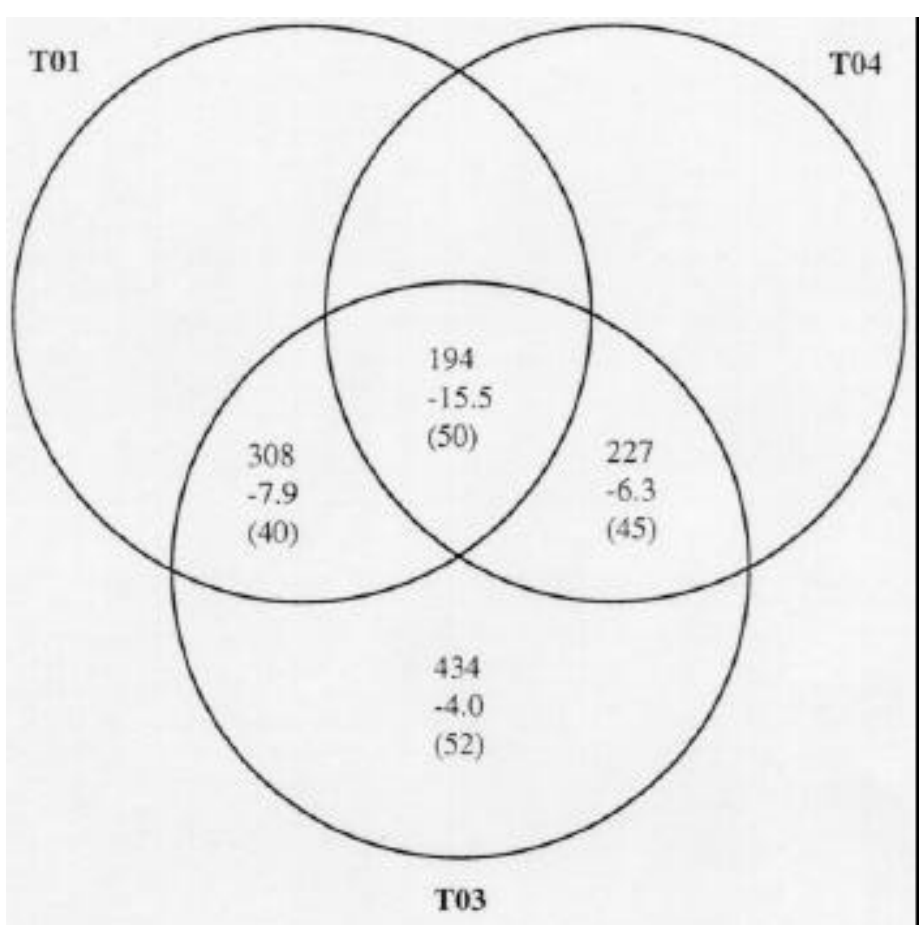

Figure 2: Relationship of T01, T04, and T03.

For T01 (Internal pollution prevention opportunity audit(s)), T04 (Participative team management), and T10 (Vendor assistance), see Figure 3.

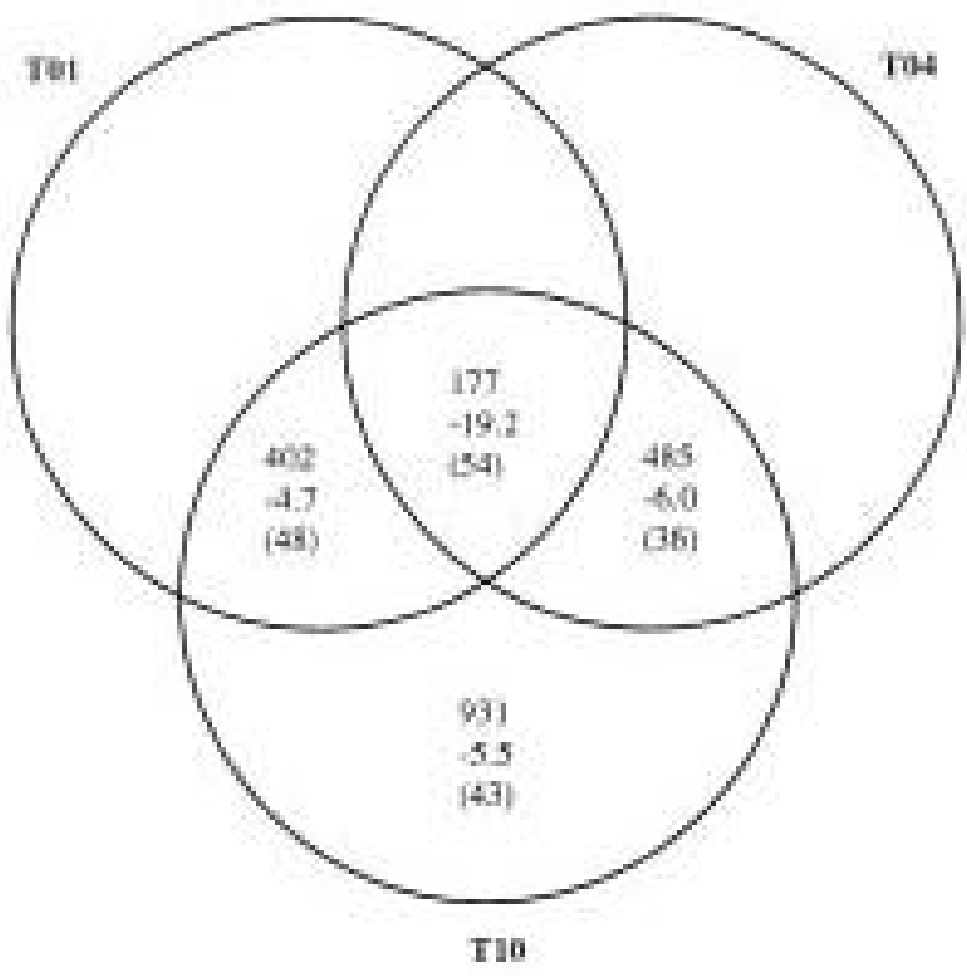

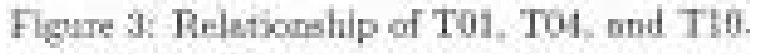

Page 11 
For both combinations, the interpretation is the same: the "external" method performs poorly without internal support; but dramatically better with internal support. This makes intuitive sense, and we discuss this further in the next section.

\section{Discussion}

Table 2 displays "one-way" comparisons of source reductions. From this perspective, internal audits (T01) and formal employee recommendations (T06) seem to be the most effective. (The high effect of Federal technical assistance has to be interpreted with care, because only 22 forms reported this method.) Note that in contrast to formal employee recommendation procedures, the informal ones (T05) show no positive effect on source reduction effect. Similarly; the effects of state technical assistance, trade association assistance (T08), and vendor assistance (T10) are negligible when taken alone, as are the effects of external audits (T02), material audits (T03), and participative team management (T04). From these results we can draw the conclusions that audits are more effective if they are conducted internally and employee recommendations only have an impact when they are established in a formal way. Both approaches have employee involvement or participation in the source reduction issue in common. This indicates that it is the serious and organized effort to involve employees in pollution prevention that is most important, and not the occasional collection of ideas. The employee needs to believe that the organization is making a serious effort to involve and empower him or her in matters of pollution prevention. As noted in §3.1,employee concern and participation is an important variable which crosses many boundaries. Since companies with this characteristic cross many industrial and geographical boundaries it does appear that participation itself is a significant contributor.

While, as mentioned, internal audits and formal employee recommendation procedures individually showed better results than most external or technical approaches, their combinations seem to be even more effective. For example, team management (T04) alone did not show an effect on source reduction, but if combined with internal audits (T01) we find a ratcheting up of results and this takes an even larger leap forward when formal employee recommendation (T06) is added to the mix (see Table 3). This suggests that even if a participatory culture exists (as would be indicated by the presence of team management), it needs to be linked formally to environmental issues to have an impact on source reduction; the broader and more intense the participatory culture around environmental issues, the broader the impact on performance. In addition, integrating nonparticipative resource reduction methods (external audits and technical assistance) with employee involvement and participation approaches enhances the formers' effectiveness too: Vendor assistance (T10), while showing 
no impact on source reduction when applied alone, in combination with internal audits (T01) and participative team management (T04) shows a strong impact on source reduction (see Figures 2 and 3). Further research is needed to determine optimal participatory strategies for maximum source reduction.

These results challenge the prevailing wisdom about environmental affairs as a matter of expert science and technology alone. Environmental action has been viewed (even in current congressional debate) as an issue of appropriate scientific certainty and the application of technical solutions to a limited set of issues. Many environmentalists have placed an emphasis on outside auditing and external pressure to improve the environment. This data challenges both sets of preconceptions. We would posit that the sum of many actions within a firm that result from a established formal participatory approach is required to implement suggestions by outside parties or advisors. To solve environmental problems not only the technical solution itself is needed, but the organizational stakeholders need to be ready and willing to make the required changes. While external resources can be of assistance (e.g., vendor assistance or material audits), both of these strategies need to be built on a platform of internal responsibility and accountability.

Pollution prevention policy needs to identify best practices and the means for expanding the range of enterprises engaged in intense employee involvement in source reduction. Considerable public revenue has been devoted to development of environmental technologies on the assumption that new machinery and tools will make a great contribution to solving environmental problems. Compliance activities including waste minimization and pollution prevention activities place a heavy reliance on outside technical experts to bring about change. While the data shows that they do have an impact, they are optimized when combined with internal employee involvement approaches. The magnitude of the potential impact is considerable; even allowing for variations in effectiveness of participative programs. If other companies adopted a broad set of participatory approaches and achieved successes comparable to the "T01-T04-T06" group (discussed in §3.1), hundreds of millions of tons of hazardous chemicals would not be released to the environment and hundreds of millions of dollars would be saved.

Efforts spent on technical assistance approaches could easily become more productive. The interdependence between technical and participatory approaches suggest combining resources provided for external assistance with efforts to build participatory infrastructures inside companies. ISO 14000 standards and government regulations need to consider how to stimulate broader employee involvement and formal participatory structures to advance the 
effectiveness of current environmental protection and improvement methods. In short, environmental outcomes would be better served if the current externally driven approach would be transformed into an internally driven approach using employee involvement and participation.

\section{Research directions}

The data analysis reported herein, though carefully done, is essentially preliminary or exploratory. Three main issues must be addressed in the next phase of this research. First, it is clear that source reduction method is not the only predictor of source reduction (as measured by PREL). Some other potential predictors are given within the TRI dataset itself, e.g., industry type (given by Standard Industrial Code), geographical region (state), and chemical type (or specific chemical). Other covariates (e.g., financial information) can be adjoined to the dataset by linking to other databases; in principle this can be done, for example, via Dun and Bradstreet number. Some information of interest may only be accessible via direct contact with the company; which entails a questionnaire survey, necessarily on a small sample of TRI respondents. We are currently working on such a survey.

Second, given adequate information on covariates, it is preferable to search systematically for the best predictors of source reduction, and for the values of these predictors that lead to the greatest quantity of source reduction (as measured by median PREL). Since many of the covariates are categorical (SIC, region, etc.), we envision using some method of reducing high-dimensional contingency tables, such as correspondence analysis, to clarify the structure of the data. Formal statistical analysis would then proceed by estimating median PREL via a nested or hierarchical model that would include terms for the effects of the various predictors. ("Nested effects" arise, for example, due to the fact that each parent company may have several facilities, each of which may have several chemicals.) The latter analysis will be nonparametric, because of the considerations mentioned in $\S 3$, and this will push the boundaries of nonparametric analysis of such models. In principle, though. existing statistical methodology should be adequate to the task.

Third, it is important to situate this research within the larger context of research on HR management strategies and organizational outcomes. Existing research of this type has dealt with the relationship of employee participation and measures of organizational effectiveness such as human resource outcomes. productivity, or specific financial measures (Dyer and Reeves 1994: MacDuffie 1995). The link to pollution prevention and toxic emissions seems to be relatively unexplored. But some ideas and conceptual frameworks from previous research are applicable to this problem as well. Ultimately, we hope to determine the relative importance 
of human resource strategies among predictors of source reduction, and which combinations of these strategies constitute "best practice." 


\section{References/Endnotes}

[1] Dyer, L., and Reeves. T. (1994). HR strategies and firm performance: What do we know and where do we need to go? CAHRS Working Paper 94-29. (Center for Advanced Human Resource Studies, Cornell University, Ithaca, NY.)

[2] Kornbluh, H., Crowfoot, J., and Cohen- Rosenthal, E. (1985). Worker participation in energy and natural resource conservation. International Labour Review 124, 737-753.

[3] Macduffie. J.P. (1995). Human resource bundles and manufacturing performance: organizational logic and flexible production systems in the world auto industry. Industrial anal Labor Relations Review 48, 197-221.

(4) U.S. Environmental Protection Agency (1993). 1991 Toxics Release Inventory Public Data, Release. EPA 745-R-93-003.

[5] Work and Environment Initiative (1994). Work and the Environment Bibliography, Work and Environment Initiative, New York State School of Industrial and Labor Relations, Cornell University, Ithaca, NY.

[6] John Bunge, Edward Cohen-Rosenthal, and Antonio Ruiz-Quintanilla, Cornell University, May 1, 1995. 


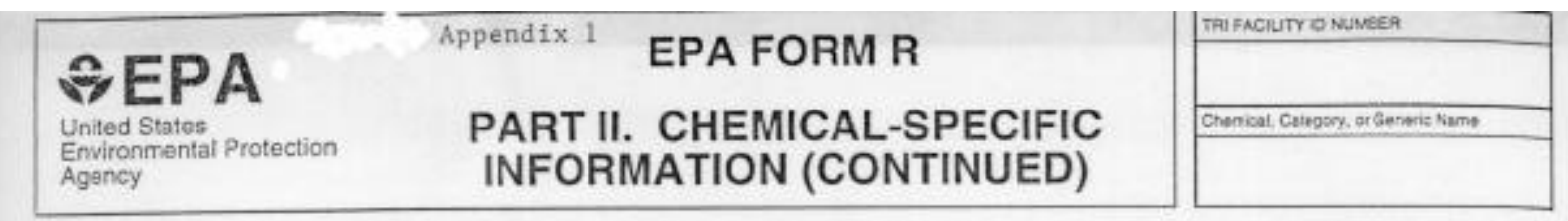

\begin{tabular}{|c|c|c|c|c|c|c|}
\hline \multicolumn{2}{|c|}{$\begin{array}{l}\text { All quantity estimates can be reported } \\
\text { using up to two significant figures. }\end{array}$} & \multirow[t]{2}{*}{$\begin{array}{l}\text { Column A } \\
1991 \\
\text { (poundsyear) }\end{array}$} & \multirow[t]{2}{*}{$\begin{array}{l}\text { Column B } \\
1992 \\
\text { (poundsyear) }\end{array}$} & \multicolumn{2}{|l|}{$\begin{array}{l}\text { Column C } \\
1993 \\
\text { (poundsyear) }\end{array}$} & $\begin{array}{l}\text { Column D } \\
1994 \\
\text { (pounds/year) }\end{array}$ \\
\hline 8.1 & Quantity released ${ }^{*}$ & & & & & \\
\hline 8.2 & $\begin{array}{l}\text { Quantity used for energy } \\
\text { recovery on-site }\end{array}$ & & & & & \\
\hline 8.3 & $\begin{array}{l}\text { Quantity used for energy } \\
\text { recovery off-site }\end{array}$ & & & & & \\
\hline 8.4 & Quantity recycled on-site & & & & & \\
\hline 8.5 & Quantity recycled off-site & & & & & \\
\hline 8.6 & Quantity treated on-site & & & & & \\
\hline 8.7 & Quantity treated off-site & & & & & \\
\hline 8.8 & $\begin{array}{l}\text { Quantity released to the en } \\
\text { remedial actions, catastrop } \\
\text { not associated with produc }\end{array}$ & $\begin{array}{l}\text { ironment as a } \\
\text { hic events, or } \\
\text { ion processes }\end{array}$ & $\begin{array}{l}\text { sult of } \\
\text {-time events } \\
\text { pounds/year) }\end{array}$ & & & \\
\hline 8.9 & Production ratio or activity & index & & & & \\
\hline \multirow[t]{2}{*}{8.10} & \multicolumn{6}{|c|}{$\begin{array}{l}\text { Did your facility engage in any source reduction activities for this chemical during } \\
\text { the reporting year? If not, enter "NA" in Section 8.10.1 and answer Section 8.11. }\end{array}$} \\
\hline & $\begin{array}{l}\text { Source Reduction Activities } \\
\text { [enter code(s)] }\end{array}$ & \multicolumn{5}{|c|}{ Methods to Identify Activity (enter codes) } \\
\hline 8.10 .1 & & a. & \multicolumn{2}{|l|}{ b. } & \multicolumn{2}{|l|}{ c. } \\
\hline 8.10 .2 & & a. & \multicolumn{2}{|l|}{ b. } & \multicolumn{2}{|l|}{ c. } \\
\hline 8.10 .3 & & a. & \multicolumn{2}{|l|}{ b. } & \multicolumn{2}{|l|}{ c. } \\
\hline \multicolumn{2}{|l|}{8.10 .4} & a. & b. & & c. & \\
\hline 8.11 & \multicolumn{5}{|c|}{$\begin{array}{l}\text { Is additional optional information on source reduction, recycling, or } \\
\text { pollution control activities included with this report? (Check one box) }\end{array}$} & YES \\
\hline \multicolumn{7}{|c|}{$\begin{array}{l}\text { * Report releases pursuant to EPCRA Section } 329(8) \text { including "any spilling, leaking, pumping, pouring, emitting, emptying, discharging. } \\
\text { injecting, escaping, leaching, dumping, or disposing into the environment." Do not include any quantity treated on-site of off-site. }\end{array}$} \\
\hline
\end{tabular}

